\title{
Obesity Among Male Employees at Saudi Aramco: Trends, Factors, and Johns Hopkins Aramco Healthcare Recommendations
}

\author{
Alexander Woodman ${ }^{1}$, Nizar Jaoua ${ }^{2}$ \\ ${ }^{1}$ Department of Humanities and Social Sciences, Prince Mohammad Bin Fahd University \& Saudi Commission for Health Specialties, \\ Dhahran, Saudi Arabia \\ ${ }^{2}$ Department of Mathematics and Natural Sciences, Prince Mohammad Bin Fahd University, Dhahran, Saudi Arabia
}

Email address:

awoodman $a$ pmu.edu.sa (A. Woodman), njaoua $a$ pmu.edu.sa (N. Jaoua)

\section{To cite this article:}

Alexander Woodman, Nizar Jaoua. Obesity Among Male Employees at Saudi Aramco: Trends, Factors, and Johns Hopkins Aramco Healthcare Recommendations. American Journal of Internal Medicine. Vol. 6, No. 4, 2018, pp. 73-81. doi: 10.11648/j.ajim.20180604.15

Received: June 29, 2018; Accepted: July 13, 2018; Published: August 7, 2018

\begin{abstract}
The purpose of this primary data analysis is to estimate the prevalence of obesity in a specific workplace in the Kingdom of Saudi Arabia (KSA). The information would then be used to predict the prevalence of obesity among the male workforce of Saudi Aramco, the largest oil company in the world. A total of $\mathrm{N}=1,000$ male employees (883Saudis, 117nonSaudis), aged 19-65, participated. They were randomly selected from several male Saudi Aramco stations and were asked to take a survey. Chi-square test was used to measure the significance effect of some independent variables on the BMI status. The overall prevalence was estimated, with a confidence level of $95 \%$, at $22.5 \pm 2.6 \%$ for obesity, $36.7 \pm 3 \%$ for overweight, and $1 \pm 0.6 \%$ for underweight. The figures highly depended on the region where they spent their childhood, their age, nationality, and amount of exercise performed per week. For instance, $27.4 \pm 4.2 \%$ of those who grew up in the Eastern Province were estimated to be obese (vs. $16.5 \pm 3.5 \%$ among those raised elsewhere in KSA), and $28.7 \pm 5 \%$ of those who rarely exercise (less than 1 hour per week) were considered obese (vs. 17.8 $\pm 4.1 \%$ among those who work out for at least 3 hours per week). As a result, a logistic model, involving these factors, was used for future prediction. For example, non-Saudis would be about 2.3 times more likely to be obese, and those aged 30-39 would be about 1.9 times more likely to be obese compared to "under 30" and "50 or more" age groups and 1.7 times more likely to be so than those aged 40-49. In addition, the lowest and highest conditional probabilities of obesity relative to this model were determined (6.6\% and 66.4\%). As a result, the likeliest male employees to be obese; the non-Saudi ones, raised in the Easter Province, aged 30-39 and exercise very little (less than 1h/w), would actually have more than two chances in three to be obese. Based on relatively concerning figures about obesity in male employees of Saudi Aramco, this paper recommends workplace wellness program model to improve the health of employees and their productivity, by creating an atmosphere of health and care for their well-being.
\end{abstract}

Keywords: BMI, Logistic Regression Model, Male Employees, Obesity, Odds Ratio, Saudi Arabia, Saudi Aramco, Workplace Wellness Model

\section{Background}

The prevalence of obesity has become a global public health issue. Unfortunately, Saudi Arabia has become one of the most diseased countries in the world [1]. There are many serious risks attributed to obesity which include a higher risk of diabetes, hypertension, coronary heart disease, and stroke [5, 16]. These medical issues also add significant healthcare costs for the government and the employers of these individuals [6].
Over time, employers come to understand that professional performance in a business or company is dependent on what is called the human factor. Research has shown that employers spend $40-60 \%$ of their income on employee salaries, in addition to training and development costs [14]. These costs can continue to increase if there are cases of lost productivity related to issues of employee health [14].

The information regarding the health of employees has become one of the essential reasons for the increase in employee 
health and wellness programs worldwide. Workplace wellness programs are established to promote and develop the well-being of the workforce and support public health programs [8].

The rising numbers of non-communicable diseases (NCDs) in the Middle East, mainly Saudi Arabia, has put an increased strain on the health system and its employers. Many Middle Eastern organizations have implemented the directions of affiliated health programs, which stress the importance of employee productivity. Productivity is defined as the amount of work produced based on the time and cost required to do that work [4]. Since Saudi Arabia is still a newly developing country, it continues to struggle with first world health concerns [9]. This continues to make the issue of employee health particularly vital to the people and their country [15].

In addition to other communicable and non-communicable diseases, obesity, affecting $28.6 \%$ of the population, is one of the most serious medical conditions in Saudi Arabia. It is also one of the primary risk factors that have led to a radical change in the health statistics in Saudi Arabia [4]. Obesity is associated with several chronic, non-communicable diseases (NCD). This can result in a decrease in the health-wellness of employees which can put significant pressure on healthcare outflow and the productivity of the workforce.

The connection between illness and reduced productivity makes the investment in human capital essential [2]. Work productivity loss is most often identified by absenteeism and presenteeism. Absenteeism is defined as the days of absence from work because of illness. Presenteeism occurs when an employee chooses to be at work despite feeling ill or when taking sick leave would be a better option [3]. The most effective organizational performance of a company requires and depends upon a healthy and productive workforce.

Saudi Aramco is the State-owned oil company of the Kingdom of Saudi Arabia and is a fully integrated, global petroleum and chemicals enterprise. Over the past eighty years, Saudi Aramco has become the world's largest integrated oil and gas company [10]. The company employs a workforce of over 65,000 worldwide and is considered an excellent employer, attracting many of The Kingdom's most exceptional talents. Their employees are well-educated professionals focused on doing their best work in a highlyregarded corporate environment.

One important issue is that there is a prevalence of workers with diabetes, high blood pressure, high cholesterol levels, and obesity among the employees in Saudi Aramco. The company records indicate that there are a large percentage of high and medium risk employees and only a few workers in the low-risk category. The increased rates of high-risk employees reflect significantly on the company, especially when the workforce has over 65,000 employees. Those statistics indicate a higher prevalence of chronic health conditions in this company. That further shows higher direct medical costs, higher absenteeism, higher disability and workers compensation costs, and lower productivity as a result of higher presenteeism.

This research analyzes the prevalence of obesity in male employees at Saudi Aramco. As active researchers and university faculty, we had an opportunity to collect 1,000 surveys from different branches of the company across Saudi Arabia, particularly from the Eastern Province.

\section{Methods}

This analysis was based on $\mathrm{N}=1,000$ surveys collected in 2018 from different branches of Saudi Aramco community. The data mostly came from those located in the Eastern Province of Saudi Arabia, where the authors were located. The surveys were developed in both Arabic and English.

The participants, aged 19-65, were randomly selected among employees from several male stations of Saudi Aramco. This was an appropriate sample which consisted of $38 \%$ aged under 30 or over 49 years old and $62 \%$ aged between 30 and 49 years. The subjects were asked questions regarding their socio-demographic characteristics, socioeconomic status, and their lifestyle. The lifestyle questions included, but not limited to, the level of physical activity and carbohydrate and fat intake. Prior to presenting the survey, the questionnaire was pre-tested by a randomly selected group of employees and approved by the institutional review board. All subjects provided a written consent to participate.

The data were analyzed using SPSS. The underweight, overweight, and obesity prevalence rates were calculated for the entire sample of 1,000 . Prior to the statistical analysis, the BMI was calculated for each employee, defined as the ratio of the weight (in kilograms) to the square of the height (in meters). The results were then converted into the widely known four BMI categories. The conversion was done using the international classification, specifically for adults, as prescribed by the World Health Organization [17]. The Body Mass Index (BMI) was calculated and the prevalence was determined using the international classification as prescribed by the World Health Organization [18]. Other variables, such as age, fat intake, time of exercise routine, nationality status, and the region where the subject was raised were used to examine the significance of their effect on the BMI.

According to the standard international classification used by the WHO, anyone with a BMI below 18.5 is considered to be underweight, those who are said to be in the normal range have a BMI that falls between 18.5 and 24.99, overweight or pre-obese are those who have a BMI which measures between 25 and 29.99, and anyone, whose BMI is 30 or more, falls into the obese category [13].

Cross tabulations were carried out in order to calculate the proportion of each BMI category by age and other needed variables. A Chi-Square test was used to examine the significance of the association between BMI status and these factors (a p-value of not more than 0.05 indicates a significant correlation). In addition, confidence intervals were determined to estimate the prevalence of obesity for the entire company and a logistic regression was used to predict odds ratios and conditional probabilities of obesity. 


\section{Results}

\subsection{Descriptive Characteristics of the Sample}

As given in [Table 1], the sample was composed of male employees; $88 \%$ Saudi and 12\% non-Saudi, randomly selected from different stations of Saudi Aramco, mostly from the Eastern Province of Saudi Arabia. On average, they were about 33 years old; $38 \%$ under 30 or over 49 and $62 \%$ aged 30-49. The average height was $1.73 \mathrm{~m}$, and heights were very similar (very small SD). However, this was not the case when it comes to the weight. Indeed, [Table 1] shows an average of $86 \mathrm{~kg}$ with an SD of about 16, which represents almost $19 \%$ of the average. However, the participants were overweight on average, with a BMI around 26.6 for Saudis and 28.2 for non-Saudis. As for their families, who share in general the same household, which mostly includes their grand-parents, they were composed of 6 people on average, but the size varied extensively $(\mathrm{SD} \approx 3)$. This was also the case for the monthly income, with an average of 13,000 (SAR) and an SD of 6,000 (SAR). In the sample, three salary-based majorities were identified: employees earning 5,000-9,999 (29\%), employees earning 100,000-14,999 (31\%), and employees earning at least 15,000 (31\%).

Table 1. Socio-demographic characteristics of 1,000 male employees, Saudi Aramco (2018).

\begin{tabular}{|c|c|c|c|c|}
\hline Characteristics & Categories & n (\%) & Average & SD $^{*}$ \\
\hline \multirow{2}{*}{ Nationality } & Saudi & $883(88.3)$ & \multirow[b]{2}{*}{-} & \multirow[b]{2}{*}{ - } \\
\hline & Non-Saudi & $117(11.7)$ & & \\
\hline \multirow{4}{*}{ Age (years) } & Under 30 & $281(28.1)$ & \multirow{4}{*}{33} & \multirow{4}{*}{9} \\
\hline & $30-39$ & $388(38.8)$ & & \\
\hline & $40-49$ & $227(22.7)$ & & \\
\hline & 50 or more & $104(10.4)$ & & \\
\hline Height (m) & & & 1.73 & 0.07 \\
\hline \multirow{2}{*}{$\operatorname{BMI}\left(\mathrm{kg} / \mathrm{m}^{2}\right)$} & Saudi & & 26.6 & 4.94 \\
\hline & Non-Saudi & & 28.2 & 5.22 \\
\hline \multirow{4}{*}{ Monthly income (1,000 SAR/month) } & Less than 5 & $81(8.1)$ & \multirow{4}{*}{13} & \multirow{4}{*}{6} \\
\hline & $5-9.999$ & $293(29.3)$ & & \\
\hline & $10-14.999$ & $309(30.9)$ & & \\
\hline & 15 or more & $314(31.4)$ & & \\
\hline \multirow{3}{*}{ Family size } & 3 or Less & $203(20.3)$ & \multirow{3}{*}{6} & \multirow{3}{*}{3} \\
\hline & 4 to 6 & $410(41.0)$ & & \\
\hline & 10 or More & $138(13.8)$ & & \\
\hline
\end{tabular}

* SD: Standard Deviation

\subsection{Prevalence of Underweight, Overweight and Obesity}

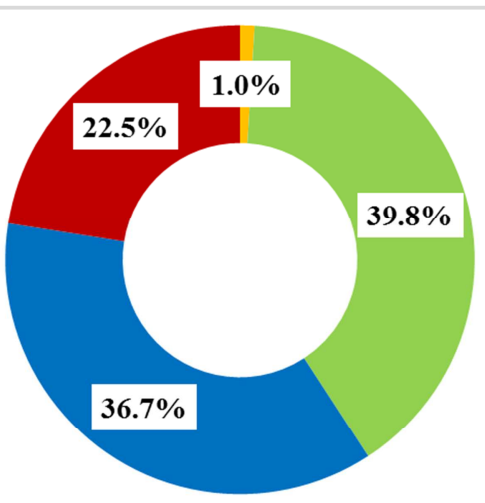

$\square$ Underweight $\square$ Normal weight $\square$ Overweight $\square$ Obese

Figure 1. Prevalence of underweight, overweight and Obesity among 1,000 male employees, Aramco (2018).

[Figure 1] shows that, among the 1,000 participants, the prevalence of underweight, overweight and obesity were respectively $1 \%, 36.7 \%$, and $22.5 \%$. However, as shown in [Figure 2], the prevalence highly depended on the region where they grew up. As for the entire male workforce of Saudi
Aramco, a straightforward calculation with a confidence level of $95 \%$ would place the prevalence at $1 \pm 0.6 \%, 36.7 \pm 3 \%$, and $22.5 \pm 2.6 \%$ for these respective BMI categories.

\subsection{Factors Having Significant Effect on the BMI}

In this survey, nine factors possibly associated with the BMI were examined. Chi-Square test was used to evaluate the statistical significance of their effect. Based on a significance level set at a $p$-value of 0.05 or less, the test revealed five significant factors sorted below in descending order of significance.

\subsubsection{Region Where the Employee Grew up}

According to [Figure 2], there were much more obese among the employees who grew up in the east of KSA (27\%) and among those who were raised outside KSA (26\%), compared to others, in particular, to those who spent their childhood in the west of the country $(13 \%)$ and to those who grew up in the south of the kingdom (14\%). However, the highest prevalence of overweight was among the employees raised outside KSA (45\%), immediately followed by the one among those who grew up in the north (40\%), whereas there were much less overweight among those who were raised in the center $(22 \%)$. As for the other childhood-related groups, the figures in terms of overweight were similar, ranging 
approximately from $35 \%$ to $37 \%$.

For the entire company, there is $95 \%$ of chance that the employees raised in the east hold the highest prevalence of obesity $(27.4 \pm 4.2 \%)$ and those who grew up outside KSA hold the highest prevalence of overweight $(44.9 \pm 8.7 \%)$.
These differences in BMI, due to the region where the employee was raised, were statistically the most significant, with a $p$-value as low as 0.00002 , compared to those related to other factors.

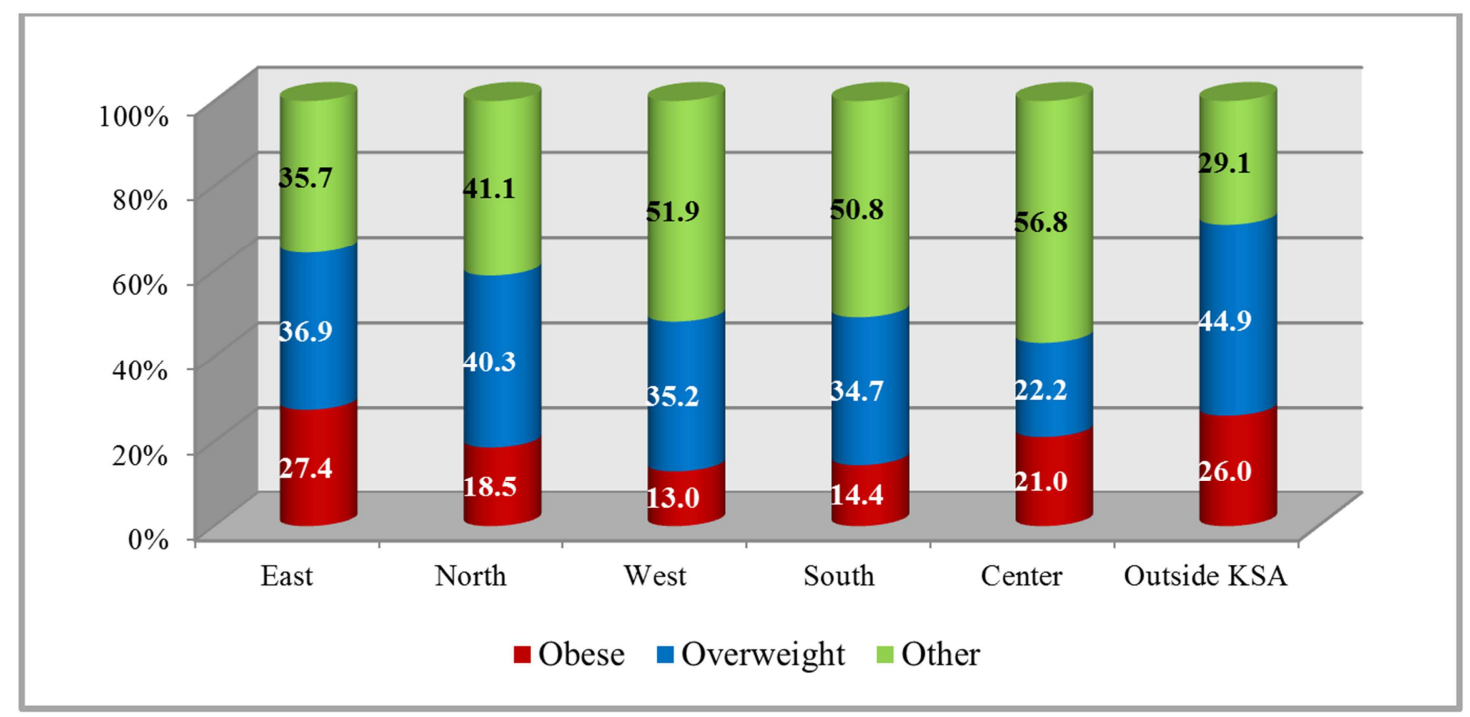

Figure 2. Prevalence of overweight and obesity by region of childhood among 1,000 male employees, Saudi Aramco (2018).

\subsubsection{Age and Nationality Status}

Regardless of the nationality, the prevalence of obesity reached its minimum (15\%) among the youngest employees (under 30) and its maximum (27\%) among the second youngest group (30-39). But in terms of overweight, the highest prevalence $(45 \%)$ was among the oldest employees (50 or more) (see [Table 2]). Nevertheless, as shown in [Figure 3], for Saudis, the least obese were among the youngest employees $(14 \%)$ and the most obese were among the oldest $(28 \%)$. As for non-Saudis, almost the opposite happened. Indeed, the second youngest group (30-39) held the highest prevalence of obesity $(39 \%)$ and the oldest employees held the lowest figure $(10 \%)$. Based on the nationality only, there was about $8 \%$ more obese in nonSaudi employees.

Statistically, all of these differences by age and by nationality were highly significant (the p-values were about 0.0002 and 0.0009 respectively).

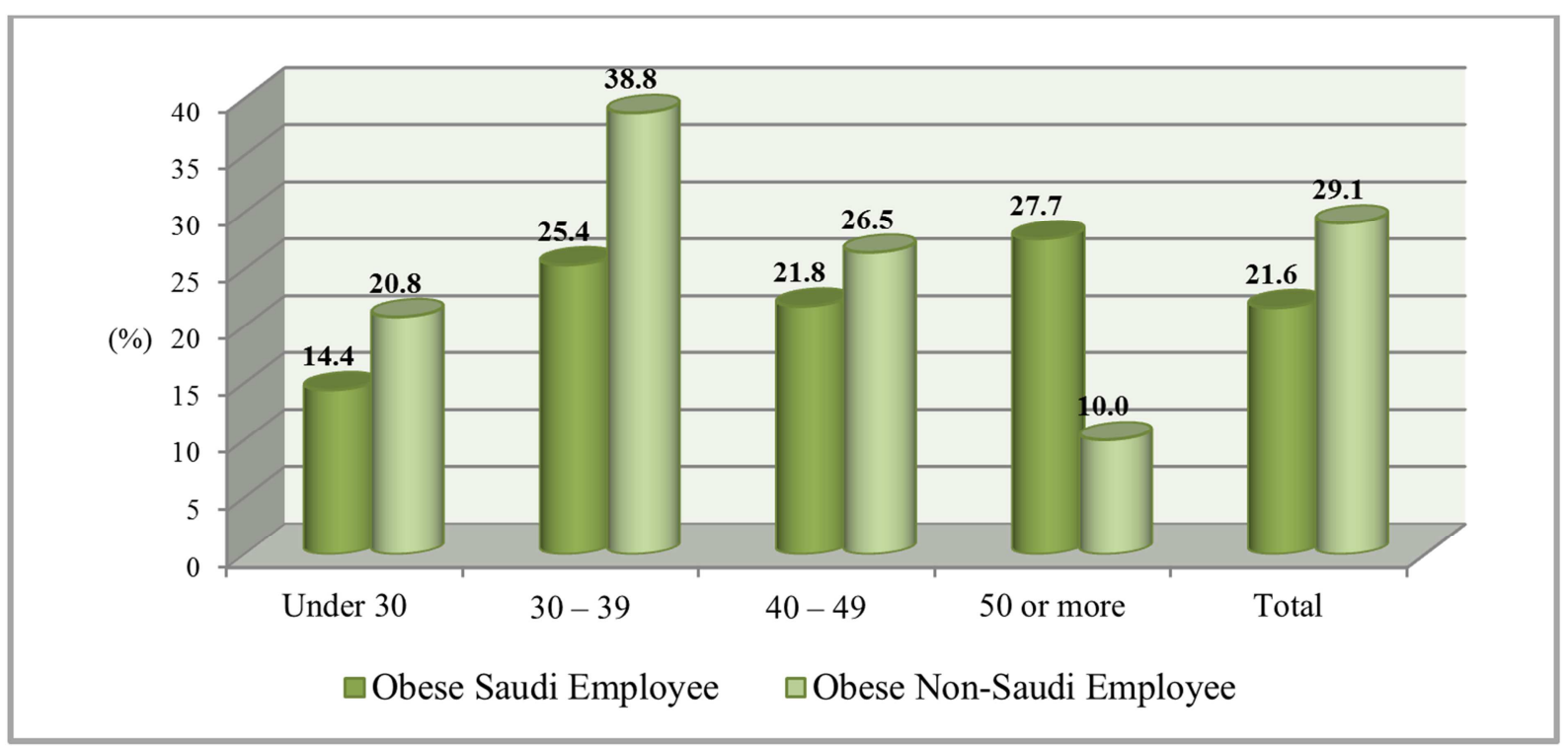

Figure 3. Prevalence of obesity by age and nationality among 1,000 male employees, Aramco (2018).

\subsubsection{Time of Exercise (Hours/Week)}

[Table 2] indicates that the sample was almost equally divided in three groups of employees, depending on the duration of their weekly exercise; less than 1hour, 1 hour to less than 3 hours, and 3 hours or more. According to [Figure 
4], the less they practiced the more obese among them there were. Indeed, the prevalence of obesity was at its highest $(29 \%)$ among the sports-nearly-free subjects and its lowest (18\%) among those who exercise for at least 3 hours per week. This was also the case when considering the regions where they grew up, except for those who were raised outside KSA, for whom exercising for 3 hours or more seemed to have no effect on the obesity, making them hold the highest prevalence $(24 \%)$, compared to the other childhood-based groups exercising for a similar period of time. In addition, while the figures were similar between those who grew up in the Eastern province and those raised outside KSA (with a maximum of obesity rate around 32$33 \%$ for each group among those exercising the least), those who grew up in other Saudi provinces held the lowest rates of obesity $(23 \%, 16 \%$, and $11 \%$ respectively among the three exercise-related groups). However, more than one third of each exercise-related group was overweight, with a maximum of $40 \%$ among the intermediate group (see [Table 2]). Overall, the differences in BMI status relative to the time of exercise were highly significant $(\mathrm{p} \approx 0.0037)$.

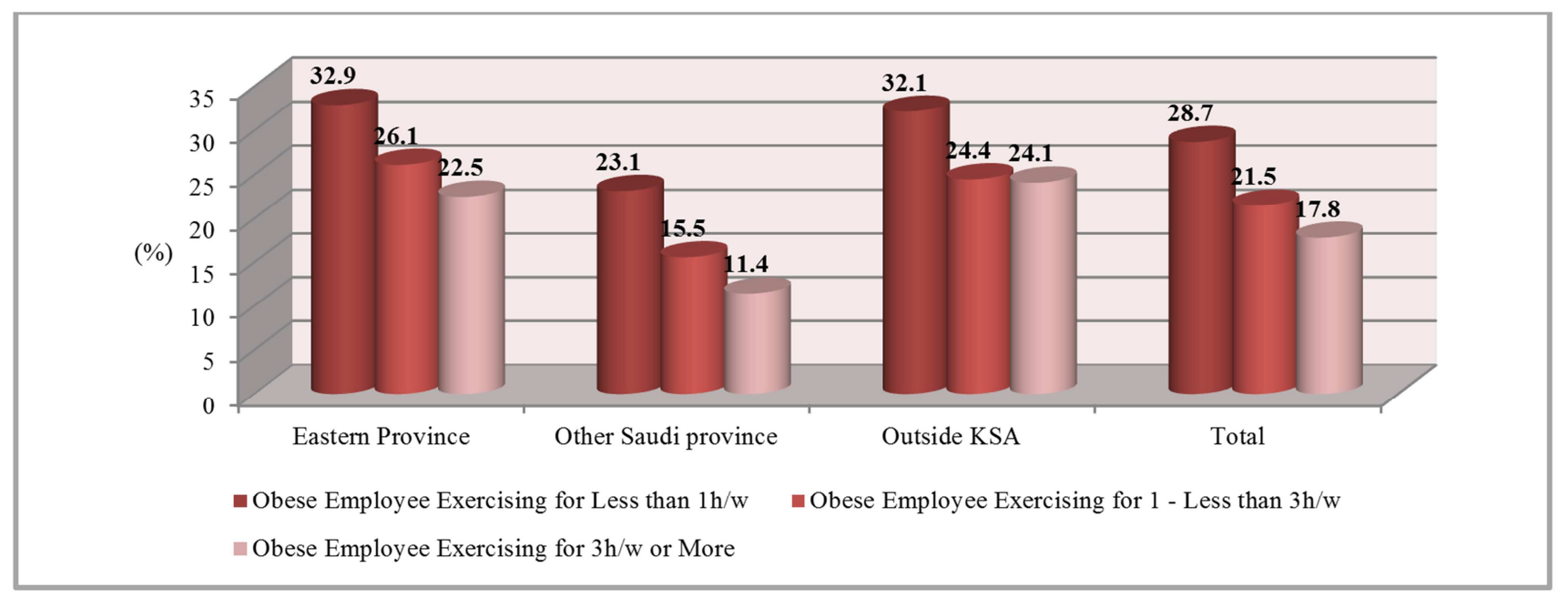

Figure 4. Prevalence of obesity by region of childhood and time of exercising among 1,000 male employees, Saudi Aramco (2018).

\subsubsection{Time of Screen-Watching (Hours/Day)}

According to [Table 2], less than one fifth of the sample claimed spending at least 6 hours per day watching screens. Among these employees, $28 \%$ were obese. However, the prevalence was slightly lower $(26 \%)$ among about one third of the sample, who spend much less time on the same activity (less than 2 hours per day). In addition, almost 19\% of the remaining half of the sample was obese. Nevertheless, the longer they stayed watching screens, the more overweight among them there were. Indeed, the prevalence of overweight was $33.5 \%, 36 \%$, and $39 \%$ respectively. Over all, the differences in BMI status due to the time of screenwatching were statistically significant ( $\mathrm{p} \approx 0.0106$ ).

Table 2. Factors having significant effect on the BMI of 1,000 male employees, Saudi Aramco (2018).

\begin{tabular}{|c|c|c|c|c|c|c|}
\hline \multicolumn{7}{|c|}{ Body Mass Index Status } \\
\hline & & Obese & Overweight & Other & Total & Chi' $^{2}$ Test \\
\hline Factor & Category & n (\%) & n (\%) & n (\%) & n (\%) & p-value \\
\hline \multirow{3}{*}{ Nationality } & Saudi & $191(21.6)$ & $313(35.4)$ & $379(42.9)$ & $883(88.3)$ & \multirow{2}{*}{0.0009} \\
\hline & Non-Saudi & $34(29.1)$ & $54(46.2)$ & $29(24.8)$ & $117(11.7)$ & \\
\hline & Under 30 & $42(14.9)$ & $96(34.2)$ & $143(50.9)$ & $281(28.1)$ & \multirow{4}{*}{0.0002} \\
\hline \multirow{3}{*}{ Age (years) } & $30-39$ & $105(27.1)$ & $133(34.3)$ & $150(38.7)$ & $388(38.8)$ & \\
\hline & $40-49$ & $51(22.5)$ & $91(40.1)$ & $85(37.4)$ & $227(22.7)$ & \\
\hline & 50 or more & $27(26.0)$ & $47(45.2)$ & $30(28.8)$ & $104(10.4)$ & \\
\hline \multirow{7}{*}{ Region of childhood } & East & $121(27.4)$ & $163(36.9)$ & $158(35.7)$ & $442(44.2)$ & \multirow{7}{*}{0.00002} \\
\hline & North & $23(18.5)$ & $50(40.3)$ & $51(41.1)$ & $124(12.4)$ & \\
\hline & West & $14(13.0)$ & $38(35.2)$ & $56(51.9)$ & $108(10.8)$ & \\
\hline & South & $17(14.4)$ & $41(34.7)$ & $60(50.8)$ & $118(11.8)$ & \\
\hline & Center & $17(21.0)$ & $18(22.2)$ & $46(56.8)$ & $81(8.1)$ & \\
\hline & Outside KSA & $33(26.0)$ & $57(44.9)$ & $37(29.1)$ & $127(12.7)$ & \\
\hline & Less than 1 & $90(28.7)$ & $107(34.1)$ & $117(37.3)$ & 314 (31.4) & \\
\hline \multirow[t]{3}{*}{ Time of exercise (hours/week) } & 1 - Less than 3 & $76(21.5)$ & $143(40.4)$ & $135(38.1)$ & $354(35.4)$ & \multirow[t]{3}{*}{0.0037} \\
\hline & 3 or More & $59(17.8)$ & $117(35.2)$ & $156(47.0)$ & $332(33.2)$ & \\
\hline & Less than 2 & $77(25.5)$ & $120(39.7)$ & $105(34.8)$ & $302(30.2)$ & \\
\hline \multirow[t]{3}{*}{ Time of screen-watching (hours/day) } & 2 - Less than 6 & $98(18.9)$ & $187(36.0)$ & $234(45.1)$ & $519(51.9)$ & \multirow[t]{3}{*}{0.0106} \\
\hline & 6 or More & $50(27.9)$ & $60(33.5)$ & $69(38.5)$ & $179(17.9)$ & \\
\hline & Total & $225(22.5)$ & $367(36.7)$ & $408(40.8)$ & $1,000(100)$ & \\
\hline
\end{tabular}




\section{Regression Analysis and Predictions}

\subsection{Multiple Regression}

Based on [Table 2], the region of childhood was the factor which association with BMI status was the most statistically significant $(\mathrm{p} \approx 0.00002)$. But three other factors (age, nationality status, and time of exercise) were also shown to have a highly significant effect on the BMI $(\mathrm{p}<0.01)$. Whereas no relevant linear correlation of the BMI involving some or all of these variables was found, a logistic regression of the obesity status was shown to be statistically highly significant $\left(\mathrm{p} \approx 1 / 10^{6}\right)$. According to the regression analysis report given in [Table 3], the odds ratios for obesity were predicted at $95 \%$ of confidence.

Table 3. Summary of logistic regression analysis predicting obesity among male employees of Saudi Aramco (2018).

\begin{tabular}{|c|c|c|c|c|c|}
\hline Predictor & Category & B & S. E. & Sig. & Odds Ratio \\
\hline \multirow{2}{*}{ Region of Childhood $^{\mathrm{a}}$} & East & .66 & .17 & .0001 & 1.931 \\
\hline & Outside KSA & -.04 & .45 & .9308 & .961 \\
\hline \multirow{3}{*}{$\operatorname{Age}^{b}$} & Under 30 & -.65 & .29 & .0252 & .521 \\
\hline & $40-49$ & -.54 & .25 & .0309 & .581 \\
\hline & 50 or more & -.66 & .19 & .0007 & .519 \\
\hline Nationality Status & Non-Saudi & .83 & .45 & .0644 & 2.282 \\
\hline Time of Exercise ${ }^{c}$ & $3 \mathrm{~h} / \mathrm{w}$ or more & -.23 & 0.20 & .2476 & .796 \\
\hline Constant & & -1.23 & .22 & $1.4 / 10^{8}$ & .292 \\
\hline
\end{tabular}

(a) Reference region: Saudi region other than East

(b) Reference age group: $30-39$

(c) Reference time interval: 1 - Less than $3 \mathrm{~h} / \mathrm{w}$

${ }^{(*)}$ Statistical significance: set at a p-value of 0.05 or less (confidence level:.05)

\subsection{Predictions of Obesity}

Two types of prediction can be made using [Table 3]; either comparing the odds for obesity between two groups of a given employee category, or estimating conditional probabilities of obesity.

In the first case, while non-Saudis would be about 2.3 times more likely to be obese, employees who grew up in the Eastern Province would be about 1.9 times more likely to be obese than those raised elsewhere in the Kingdom. The same can be said about those aged 30-39 compared to the age groups "under 30 " and "50 or more", but they would be 1.7 times more likely to be obese than the remaining group " 40 49 ". When it comes to time of exercise, those who work out very little (less than $1 \mathrm{~h} / \mathrm{w}$ ) are expected to be 1.5 times more likely to be obese than those who exercise moderately (1 to less than $3 \mathrm{~h} / \mathrm{w})$. But compared to those working out for at least $3 \mathrm{~h} / \mathrm{w}$, they would be about $1.9(\approx 1.54 / .796)$ times more likely to be obese.

$$
L=\mathrm{c}+\sum_{i} b_{i} x_{i} \approx-1.23+(-.65) * 1+.83 * 1+.66 * 1+.43 * 1 \approx .03
$$

Therefore, the probability of such an employee to be obese is estimated at:

$$
p \approx \frac{1}{1+e^{-L}} \approx \frac{1}{1+e^{-.03}} \approx .508 \approx 51 \%
$$

By a similar calculation, one can determine the lowest and highest conditional probabilities of obesity relative to this logistic regression model. As a consequence, one can show that the likeliest male employees to be obese; the non-Saudi ones, raised in the Easter Province, aged 30-39 and exercise very little (less than 1h/w), would actually have more than two chances in three to be obese. These extreme probabilities are represented in the diagram given in [Figure 5]. 




Figure 5. Extreme conditional probabilities of obesity among male employees of Saudi Aramco based on a logistic regression model.

\section{Recommendations}

In addition to the study, this research recommends that Saudi Aramco considers the following information herewith presented to employees' productivity and its growth and progress.

Johns Hopkins Aramco Healthcare Company (JHAH) is the product of a joint project between Saudi Aramco and Johns Hopkins School of Medicine (one of the world's leading academic health systems). JHAH's goal is to improve the health of a community through an innovative patientcentered care approach for employees of Saudi Aramco and other healthcare recipients [7].

Saudi Aramco supports the health and well-being of its employees, their families, and all Saudis through professional collaboration, research, and educational programs with JHAH. In order to increase employees and Saudis' knowledge on health issues, JHAH sponsors promotionalinformative events within the Company as well as in the local communities. The purpose of collaboration is to provide medical staff the opportunities to further their education, to encourage patients and their families to ask questions and gain knowledge, and to share the latest research innovations and to use them for quality patient care.

In addition to JHAH, Saudi Aramco also collaborates with the Institute for Health and Productivity Management Middle East and North Africa (IHPM- MENA). It is the leading support program for workplace wellness initiatives within the region. The IHPM-MENA understands that a healthy employee is a productive employee. This is vital for the health of a company and nation. The IHPM-MENA collects and analyzes statistics that are culturally relevant, and, at the same time, it also encourages regional organizations and companies to obtain their own workforce and healthcare statistics [10].

Saudi Aramco is considered as the regional leader concerning the population and corporate health issues. The Company has made major investments in programs to improve the health standards within Saudi Arabia. It is aware that a successful company understands that employees' health is vital to its growth and progress. Notably, an organization that invests in the well-being of its employees has lower absenteeism and higher productivity.

The University of California, Los Angeles (UCLA), is a public research University in the United States, located in the Westwood District of Los Angeles. UCLA is one of the world's most prominent research universities that excels in several disciplines and professions. At the same time, it encourages research without subject limitations. UCLA's faculty and campus community is motivated by discovery and innovation. Its original and collaborative successes, within an open and wide-ranging environment, stimulate the growth and development of its students and employees [11].

UCLA's Recreation Center implemented the "FITWELL" program as the part of the Healthy Campus Initiative (HCI), to "activate wellness" of the faculty, staff, students, and recreation members [12]. The program is designed to stimulate and motivate participants, as well as educate them in areas, such as overall wellness, stress management, general health, fitness, exercise, nutrition, and weight management. These workplace programs work to reduce the number of communicable and non-communicable diseases.

The FITWELL Program stimulates the well-being of students and employees by educating, motivating, and inspiring them to have an active fitness life. This full health care program also helps to decrease the costs of future medical assistance. The FITWELL program has a range of wellness programs to aid employees' commitment to fitness and the responsibility of self-care [12].

One of the central pods of this program, MoveWell, is to make the UCLA one of the healthiest place to work and learn and to inspire local communities and beyond. The main goal of the MoveWell pod is to broaden the impact of being active in different ways, both within and beyond UCLA Recreation, where many of the pod's programs originate. In addition to workout classes and team sports, the pod's physical fitness programs include Instant Recess and Fit Breaks, which entail short periods of activity that last all day. Fit breaks are conducted at several campus locations.

Another program designed for employees and students is the Bruin Health Improvement Plan (BHIP "Onramp"). It is a 12-week intensive training program designed to improve cardiovascular fitness and the overall strength and mobility of the participants. The BHIP. 5 program, tailored for those 
who are at least 23 kilograms overweight, combines a 3-dayper-week workout sessions, with a weekly nutritional meeting led by a registered dietitian. Within BHIP is Bruin MindFitis. It is also a 12-week mindful movement and meditation course that teaches effective stress management tools. Additionally, the FitZones program is a group exercise class which takes place during lunch break or after-work hours. Fit Breaks and Warm Up to Work is a series of fifteenminute movement breaks around campus. It could entail either a fifteen-minute stretch break or a fifteen-minute warm-up session before the person returns to work.

Workplace wellness programs, such as UCLA Recreation's FITWELL program, bring substantial benefits to UCLA and its employees through a healthy workplace culture. The addition of physical activity, along with a healthy food culture, in a business setting can be an asset to employers and employees because they help control healthcare issues.

The UCLA's HCI MoveWell pod can be a model for many big companies, particularly in Saudi Aramco. Improving employees' health, through creating an atmosphere of healthcare and wellbeing, will improve their productivity. Companies can become places where the staff feel valued and respected, not only as employees but as worthy human beings. Research has shown that these changes will decrease absenteeism and increase presenteeism (employees focus to perform their duties) of employees.

As demonstrated in the UCLA workplace wellness initiative, these programs can be a combination of group workouts or individual sessions. This program exemplifies that all employees in an organization, such as Saudi Aramco, can be included, regardless of the employee's health conditions and the shift he or she works. Nonetheless, it requires good detailed planning for it to succeed. For example, each employee should seek a medical examination and advice on the appropriate wellness program he or she should adopt. The recommendation of a fitness training program should be made in collaboration with the employee's doctors. Along with medical care, these programs should be an unconditional part of Saudi Aramco's employee wellness program.

Following the program planning phase, a baseline database recording the health and productivity status of the employees should be generated. This data will allow the employer to evaluate the health needs of the staff and use the information to improve the programs. The workplace may also become a 'unique' area, where employees can gather not only to share their stories, but to also receive new information about selfcare and wellness.

\section{Discussion}

\subsection{Limitations}

Although the research has achieved its aims, there were some predictable limitations. Firstly, the sample consisted of males only (female employees represent only $8 \%$ of Aramco). Consequently, the results only apply to the male population of the company. The researchers would have liked to include female participants in order to get more representative outcomes. Secondly, the effect of the family income was not significant on obesity. Possibly, this may be due to some participants who may not have given true responses to questions regarding family income in order to conceal the information from their co-workers. Finally, there was a lack of available data.

\subsection{Strengths}

This study was based on a huge number of data individually collected from a large sample of male employees in the largest oil company in the world. In addition, four variables were found to have a highly significant effect on the BMI status: childhood place, age, nationality status, and time of exercise. They were used as predictors in a logistic regression, where the association with the obesity status was highly significant $\left(\mathrm{p} \approx 1 / 10^{6}\right)$. The result in logistic model was used to predict obesity among male employees of the whole company.

\section{Conclusion}

This survey was conducted on $\mathrm{N}=1,000$ male employees from different branches of Saudi Aramco. The results highly depended on the region where they spent their childhood, the age, the nationality status, and the time of exercise. Based on this large sample, the overall prevalence of obesity, overweight, and underweight for the entire company was estimated at $22.5 \pm 2.6 \%, 36.7 \pm 3 \%$, and $1 \pm 0.6 \%$ respectively. With the same confidence level (95\%), it was shown that there were $29.1 \pm 8.2 \%$ of obese among non-Saudis (vs. $21.6 \pm 2.7 \%$ among Saudis), $27.4 \pm 4.2 \%$ among those who grew up in the Eastern Province (vs. 16.5 $\pm 3.5 \%$ among those raised elsewhere in KSA), $27.1 \pm 4.4 \%$ among those aged 30 39 (vs. $14.9 \pm 4.2 \%$ among under 30 group), and $28.7 \pm 5 \%$ among those who exercise for less than $1 \mathrm{~h} / \mathrm{w}$ (vs. $17.8 \pm 4.1 \%$ among those who work out for at least $3 \mathrm{~h} / \mathrm{w}$ ).

A logistic regression model involving these variables was used to predict, with $95 \%$ of confidence, either the odds ratios or conditional probabilities of obesity among male employees of the company. For example, non-Saudis would be about 2.3 times more likely to be obese. Those who grew up in the Eastern Province would be about 1.9 times more likely to be obese than those raised elsewhere in the kingdom. The same odds ratio would apply to those who rarely work out (less than $1 \mathrm{~h} / \mathrm{w}$ ) compared to those who exercise for at least $3 \mathrm{~h} / \mathrm{w}$. In addition, the lowest and highest conditional probabilities of obesity based on this model were determined $(6.6 \%$ and $66.4 \%$ ). As a result, the likeliest male employees to be obese; the non-Saudi ones, raised in the Easter Province, aged 30-39 and exercise very little (less than $1 \mathrm{~h} / \mathrm{w}$ ), would actually have more than two chances in three to be obese.

\section{Conflict of Interest}

The authors have no affiliations with or involvement in 
any organization or entity with any financial interest in the subject matter or materials discussed in the manuscript.

\section{References}

[1] Bull F., Dvorak J. Tackling Chronic Disease Through Increased Physical Activity in the Arab World and the Middle East: Challenge and Opportunity. Br J Sports Med. (2013). 47 (10):600-602. doi: 10.1136/bjsports-2012-092109.

[2] Gardner H. H. \& Gardner B. D. (2012). Health as Human Capital: Theory and Implications. A New Management Paradigm. Retrieved from: http://www.hcmsgroup.com/wpcontent/uploads/2012/05/WP01-HHC-Theory-andImplications-2012-01-161.pdf.

[3] Goettler A., Grosse A., Sonntag D. Productivity Loss Due to Overweight and Obesity: A Systematic Review of Indirect Costs (2017). BMJ Open; 7:e014632. doi: 10.1136/bmjopen2016-014632.

[4] Hayman S. The Relationship between Health Risk and Workplace Productivity in Saudi Arabia. (2016). Retrieved from:https://scholarworks.waldenu.edu/cgi/viewcontent.cgi?ar ticle $=4137 \&$ context $=$ dissertations.

[5] Al - Hazzaa H. M. Rising trends in BMI of Saudi Adolescents: Evidence from Three National Cross Sectional Studies (2007). Asia Pac J ClinNutr; 16 (3):462-6.

[6] Hruby A. \& Frank B. Hu. The Epidemiology of Obesity: A Big Picture (2015). Retrieved from: https://www.ncbi.nlm.nih.gov/pmc/articles/PMC4859313/.

[7] Johns Hopkins Aramco Healthcare. Retrieved from: http://www.jhah.com/about-JHAH.aspx.

[8] Mattke S., Liu H., Caloyeras J., Huang Ch. Y., Van Busum K. R., Khodyakov D., \& Shier V. (2013). Workplace Wellness Programs Study. Retrieved from: https://www.ncbi.nlm.nih.gov/pmc/articles/PMC4945172/.
[9] Al Othanimeen Al, Al - Nozha M., Osman Ak. Obesity an Emerging Problem in Saudi Arabia; Analysis of data from National Nutrition Survey (2007). East Mediterranean Health Journal; 13 (2): 441-8.

[10] Saudi Aramco (2018). Retrieved from: http://www.saudiaramco.com/en/home/about/who-weare.html.

[11] The University of California, Los Angeles (2018). Retrieved from: http://www.ucla.edu/about/history.

[12] The UCLA Recreation FITWELL Program (2018). Retrieved from: https://www.recreation.ucla.edu/fitwell.

[13] U. S. Department of Health and Human Services (2012). Retrieved from:https://www.niddk.nih.gov/healthinformation/health-statistics/overweight-obesity.

[14] World Economic Forum. The Global Competitiveness Report (2012-2013). Retrieved from: http://www3.weforum.org/docs/WEF_GlobalCompetitiveness Report_2012-13.pdf.

[15] World Health Organization. Country Cooperation Strategy for WHO and Saudi Arabia (2012-2016). Retrieved from: http://apps.who.int/iris/handle/10665/113227.

[16] World Health Organization. Obesity; Preventing and Managing the Global Epidemic. Report of a WHO Consultation on Obesity (2007). Geneva: World Health Organization.

[17] World Health Organization. Nutrition in Adolescence: Issues and Challenges for the Health Sector (2004). Geneva: World Health Organization.

[18] World Health Organization. Body Mass Index Global Database on Body Mass Index (2006). Retrieved from: http://www.assessmentpsychology.com/icbmi.htm. 